\title{
An Overlooked Potentially Treatable Disorder: Idiopathic Mesenteric Panniculitis
}

\author{
Abdurrahman Sahin ${ }^{a}{\text { Hakan } \text { Artas }^{\mathrm{b}} \text { Yesim Eroglu }}^{\mathrm{b}}$ Nurettin Tunc ${ }^{\mathrm{a}}$ \\ Ulvi Demirel $^{\mathrm{a}} \quad$ Ibrahim Halil Bahcecioglu ${ }^{\mathrm{a}}$ Mehmet Yalniz ${ }^{\mathrm{a}}$ \\ ${ }^{a}$ Division of Gastroenterology and Hepatology and ${ }^{b}$ Department of Radiology, Firat University School of \\ Medicine, Elazig, Turkey
}

\section{Significance of the Study}

- In this study, patients with idiopathic mesenteric panniculitis (MP) presented with severe pain and were successfully treated with nonsteroidal anti-inflammatory drugs (NSAID) and antibiotics. This finding indicates that the inflammation in this patient subgroup might be of an infectious origin. Hence, antibiotics and NSAID could be considered in the treatment of symptomatic MP cases.

\section{Keywords}

Idiopathic mesenteric panniculitis · Treatment · Antibiotics · Nonsteroidal anti-inflammatory drugs

\begin{abstract}
Objective: The aim of this study was to determine the prevalence of mesenteric panniculitis (MP) and to describe its clinical characteristics, therapy, and outcome. Subjects and Methods: This retrospective study was carried out among patients with MP based on computed tomography (CT) scans from January 2012 to December 2015. The CT images were reanalyzed by study radiologists to confirm the previous MP diagnosis. Patients were divided into 2 groups, i.e., idiopathic and secondary, based on the presence or absence of associated predisposing factors such as trauma, malignancy, autoimmune disorders, ischemia, or previous ab-
\end{abstract}

\section{KARGER}

E-Mail karger@karger.com www.karger.com/mpp

This is an Open Access article licensed under the Creative Commons

\section{The Author(s) \\ Published by S. Karger AG, Basel \\ Karger \\ Open access} Attribution-NonCommercial-4.0 International License (CC BY-NC) (http://www.karger.com/Services/OpenAccessLicense), applicable to the online version of the article only. Usage and distribution for commercial purposes requires written permission. dominal surgery. The clinical characteristics of the 2 groups, as well as treatments, were assessed. Results: Among the 19,869 CT scans, 36 patients $(0.18 \%)$ with MP were identified (i.e., 19 [53\%] females and 17 [47\%] males). The median age was 54 years (range 26 - 76). Twenty-four patients (67\%) were categorized into the idiopathic group. Malignancy was the predisposing factor in 8 (22\%) of those patients. Furthermore, abdominal pain was the cardinal symptom observed in 22 patients (92\%) in the idiopathic group. In the idiopathic group, 15 patients (63\%) were treated with antibiotics and $16(67 \%)$ were treated with nonsteroidal anti-inflammatory drugs (NSAID). One unresponsive patient was treated with colchicine. Symptomatic relief was achieved in all of the treated patients. Conclusion: In this study, a symptomatic idiopathic subgroup of patients with MP did not have any associated disorder. The response to treatment with antibiotics and NSAID was effective in most of the patients. Based
Abdurrahman Sahin

Division of Gastroenterology and Hepatology Firat University School of Medicine

Yunus Emre Avenue 20, TR-23119 Elazig (Turkey)

E-Mail asahin@ firat.edu.tr 
on these findings, anti-inflammatory treatments beyond NSAID and surgery should be reserved for patients who are unresponsive to antibiotics and NSAID.

(C) 2017 The Author(s)

Published by S. Karger AG, Basel

\section{Introduction}

Mesenteric panniculitis (MP) is a rare, nonspecific fibroinflammatory disorder of unknown etiology that affects the adipose tissue of the root of the mesentery [1]. It consists of 2 pathological subgroups: inflammatory and fibrotic lesions. When inflammation and fat necrosis predominate over fibrosis, the condition is known as MP. Conversely, when fibrosis and retraction predominate, it is called sclerosing mesenteritis [1-3]. The gold standard for the diagnosis of MP is to demonstrate inflammatory and fibrotic changes in the mesentery histopathologically [3].

However, MP is usually suspected with MP-like findings on computed tomography (CT) scans incidentally during investigations into other disorders $[4,5]$. In large series, imaging findings consistent with MP were reported in $0.16-2.5 \%$ of patients undergoing abdominal CT for various indications $[6,7]$. In addition to asymptomatic cases, MP could be associated with several symptoms, including abdominal pain, nausea, vomiting, diarrhea, constipation, fever, weight loss, and chylous ascites [8]. Although it is frequently managed conservatively, treatment is warranted in advanced or progressive cases [9]. Various drugs have been used to treat MP, including corticosteroids, colchicine, cyclophosphamide, azathioprine, tamoxifen, and thalidomide, as well as hormonal therapies $[10,11]$. However, the previous therapeutic interventions have shown varying degrees of success. Surgery is another option in refractory cases $[12,13]$.

MP is thought to be associated with trauma, abdominal malignancy, autoimmune disorders, ischemia, or previous abdominal surgery [8]. Malignancy is the most commonly cited disorder in relation to MP [6]. The aim of this retrospective analysis was to describe the clinical characteristics of patients with MP and to investigate its management and outcome.

\section{Subjects and Methods}

This retrospective study was carried out at the Firat University Hospital, Elazig, Turkey. The radiological reports of patients who had undergone abdominal CT and were aged $\geq 18$ years of were obtained from the hospital's database using the keywords "mesen- teric panniculitis" and "sclerosing mesenteritis" from January 2012 to December 2015. The CT images were subsequently reassessed by radiologists (H.A. and Y.E.) to confirm the presence of radiologic characteristic features of MP. The radiologic diagnosis of MP was defined according to the study of Coulier [5], which defined 5 typical CT signs: (i) the presence of a well-defined "mass effect" on neighboring structures, (ii) constituted by mesenteric fat tissue of an inhomogeneous higher attenuation than adjacent retroperitoneal or mesocolonic fat, (iii) containing small soft tissue nodes, (iv) a fatty "halo sign" indicating the preservation of a halo of fat around the involved vessels; and (v) a hyper-attenuating pseudocapsule. The diagnosis of MP was established if 3 of these signs were present (Fig. 1a, b). Demographic features, complaints, clinical features, and treatments were also retrieved from the hospital database. Laboratory measurements, including white blood cell counts, hemoglobin, platelet counts, the mean platelet volume and red cell distribution width, fasting glucose, liver function tests, blood urea nitrogen, creatinine, and total protein and albumin values were also obtained from the hospital database. The study population was divided into 2 subgroups: patients with MP secondary to malignancy, such as a rheumatologic disease or a history of previous abdominal surgery, and patients with no related disorder. The latter group was called "idiopathic MP." Ethical approval for this study was obtained from the Institutional Review Board of the Firat University Faculty of Medicine.

\section{Statistical Analysis}

Descriptive statistics were used to analyze the data. Categorical variables are expressed as numbers (\%). Continuous variables are expressed as medians (range). Categorical variables were compared using the $\chi^{2}$ test or Fischer's exact test. Differences between continuous variables were analyzed using the Mann-Whitney $U$ test. $p<0.05$ was considered statistically significant. Statistical analyses were performed using the Statistical Package for the Social Sciences $\left(\right.$ SPSS $^{\circledR}$ ) for Windows (v. 21.0; SPSS, USA).

\section{Results}

Among a total of 19,869 abdominal CT examinations, 36 patients $(0.18 \%)$ were diagnosed with MP. Of those 36 patients, 19 (53\%) were female and 17 (47\%) were male. The median age of the women was 54 years (range 26-76), and that of the men was 54 years (range 32-76). Of the 36 patients, $24(67 \%)$ were in the idiopathic group and 12 (33\%) were in the secondary group. The major complaint was abdominal pain, which was present in $26(72 \%)$ patients with MP. Other MP-related symptoms were nausea and vomiting in $1(3 \%)$ patient and diarrhea in another (3\%) patient.

Based on the diagnostic criteria of Coulier [5], "sign 2" and "sign 3" were present in the whole study population. Twenty-four patients (66\%) had a mass effect (sign 1). A hyperattenuating pseudocapsule (sign 5) was evident in $29(80 \%)$ patients. The least common radiologic feature 

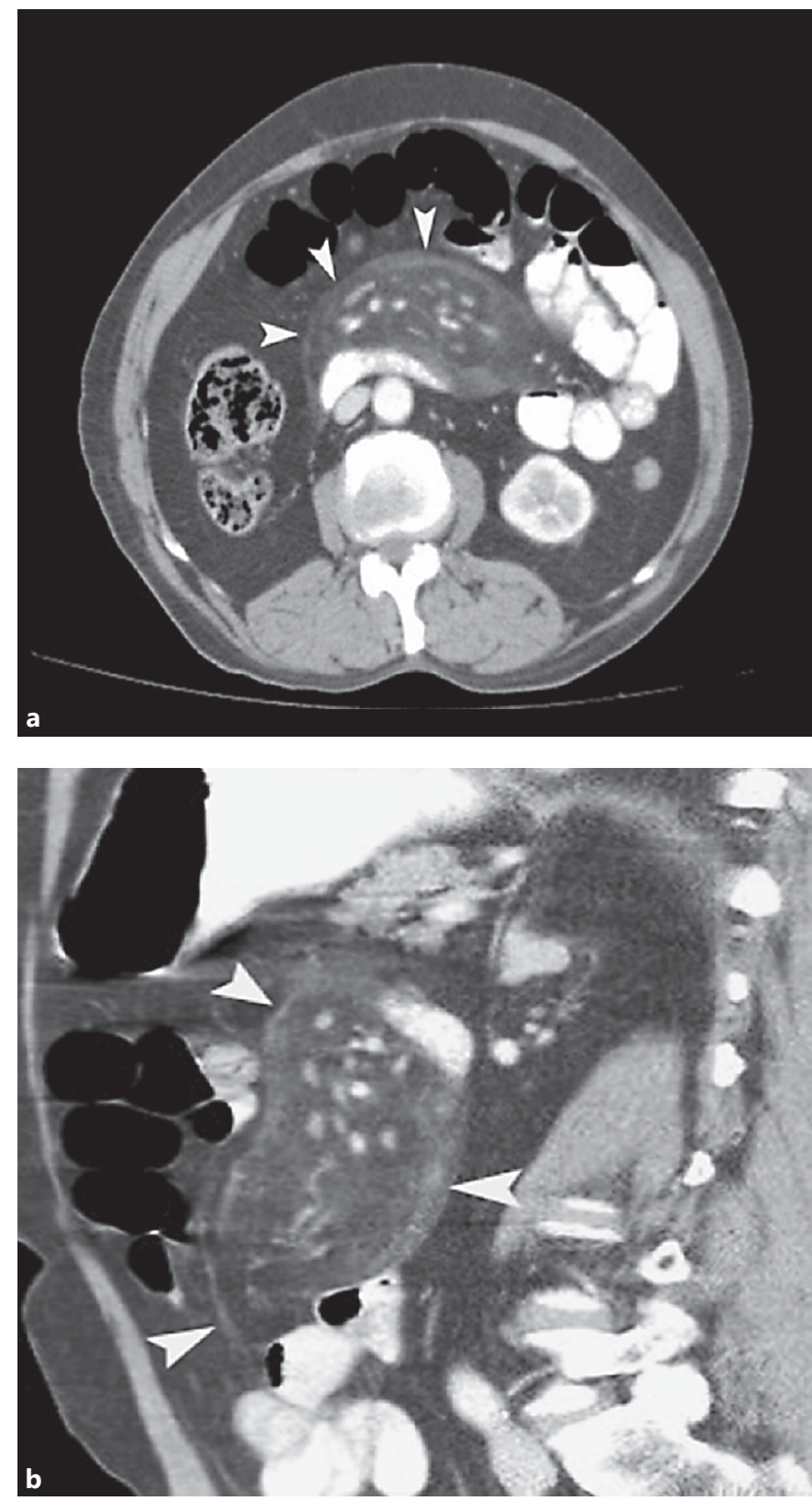

Fig. 1. Seventy-six-year-old man with chronic heart failure and acute cholecystitis. Contrast-enhanced axial (a) and coronal (b) abdominal computed tomography images showing mesenteric panniculitis as a well-circumscribed, inhomogeneous fatty mass displaying a higher attenuation than normal retroperitoneal fat with a hyperattenuating pseudocapsule (arrowheads).

was a fatty halo sign (sign 4 ), which was detected in only $2(5.6 \%)$ patients.

The secondary group was composed of 12 patients in whom MP was found in conjunction with selected disorders or major surgery. The mean age was 55.5 years (range
Table 1. Comparison of idiopathic mesenteric panniculitis and secondary mesenteric panniculitis

\begin{tabular}{llll}
\hline & $\begin{array}{l}\text { Idiopathic } \\
\text { group }\end{array}$ & $\begin{array}{l}\text { Secondary } \\
\text { group }\end{array}$ & $p$ \\
\hline Patients & 24 & 12 & \\
Age, years & $53(26-76)$ & $55.5(34-72)$ & 0.65 \\
Female/male ratio & $11 / 13$ & $8 / 4$ & 0.30 \\
\hline Cardinal symptoms & & & \\
Asymptomatic & $2(8)$ & $6(50)$ & \\
Abdominal pain & $22(92)$ & $4(33)$ & \\
Fever and dysuria & 0 & $1(8)$ & \\
Dyspnea & 0 & $1(8)$ & \\
Nausea-vomiting & 1 & 0 & \\
Diarrhea & 1 & 0 & \\
\hline Abdominopelvic surgery & $2(8)$ & $1(8)$ &
\end{tabular}

Associated disorders

Malignancy

Colorectal carcinoma 2

Pancreas carcinoma $\quad 2$

Renal cell carcinoma $\quad 1$

Bladder carcinoma 1

Breast carcinoma 1

Over carcinoma 1

Rheumatologic disorders

Ankylosing spondylitis $\quad 1$

Scleroderma 1

Miscellaneous

Portal vein thrombosis 1

Nephrolithiasis 5

Acute cholecystitis $\quad 1$

Diabetes mellitus 3

COPD 1

Heart failure 1

Values are presented as numbers, medians (range), or numbers (\%) unless otherwise stated. COPD, chronic obstructive pulmonary disease.

34-72) and 4 of them were men. Six of them were asymptomatic at the time of CT examination. The complaint of 1 patient who had been diagnosed with breast cancer was dyspnea. Fever and dysuria related to urinary tract infection were the admission symptoms in another patient with bladder carcinoma. Four patients in this group had abdominal pain (2 patients had pancreas carcinoma). One patient had a previous abdominal surgery due to intestinal perforation and 1 patient had portal vein thrombosis. MP was related to malignancy in 8 (22\%) patients, i.e., 2 with colorectal carcinoma, another 2 with pancreatic carcinomas, and 4 each with renal cell carcinoma, 
Table 2. Demographic and clinical characteristics and treatments of patients with idiopathic mesenteric panniculitis

\begin{tabular}{|c|c|c|c|c|c|c|}
\hline $\begin{array}{l}\mathrm{Pa}- \\
\text { tient } \\
\text { No. }\end{array}$ & $\begin{array}{l}\text { Age, } \\
\text { years }\end{array}$ & Sex & Symptoms & $\begin{array}{l}\text { Asso- } \\
\text { ciated } \\
\text { disorder }\end{array}$ & Treatment & Other information \\
\hline 2 & 63 & M & Asymptomatic & DM & None & $\begin{array}{l}\text { duodenal diverticula, } \\
\text { nephrolithiasis }\end{array}$ \\
\hline 3 & 51 & M & Right lower quadrant pain & $\mathrm{DM}$ & Etodolac $600 \mathrm{mg}$ po bid for 8 days & \\
\hline 4 & 76 & $\mathrm{~F}$ & Epigastric pain & None & Dexketoprofen $25 \mathrm{mg}$ po bid for 10 days & \\
\hline 6 & 45 & $\mathrm{~F}$ & Suprapubic pain & None & Dexketoprofen $25 \mathrm{mg}$ po bid for 13 days & \\
\hline 7 & 48 & M & Left flank pain & $\mathrm{CAD}$ & Nimesulid $100 \mathrm{mg}$ po bid for 7 days & \\
\hline 8 & 43 & $\mathrm{~F}$ & Periumbilical pain & None & Diclofenac $50 \mathrm{mg}$ po bid for 7 days and ciprofloxacin & \\
\hline 9 & 61 & $\mathrm{M}$ & Left upper quadrant pain, diarrhea & CAD & Ciprofloxacin & \\
\hline 10 & 63 & $\mathrm{~F}$ & Epigastric pain & CAD, HT & Naproxen $750 \mathrm{mg}$ po qd for 10 days & \\
\hline 11 & 58 & $\mathrm{~F}$ & Left flank pain & None & Cefpodoxime & \\
\hline 16 & 32 & M & Periumbilical pain & None & Ceftriaxone & \\
\hline 17 & 65 & M & Right lower quadrant pain & None & $\begin{array}{l}\text { Dexketoprofen } 50 \mathrm{mg} \text { i.v. bid for } 4 \text { days and then } \\
\text { dexketoprofen } 25 \mathrm{mg} \text { i.v. bid for } 5 \text { days and cefuroxime }\end{array}$ & Ureterolithiasis \\
\hline 18 & 35 & $\mathrm{~F}$ & Right flank pain & None & Naproxen $750 \mathrm{mg}$ po qd for 8 days and cefuroxime & Nephrolithiasis \\
\hline 19 & 71 & $\mathrm{~F}$ & Periumbilical pain, nausea-vomiting & CAD, COPD & Dexketoprofen $50 \mathrm{mg}$ i.v. bid for 13 days and ceftriaxone & \\
\hline 20 & 49 & M & Left lower quadrant pain & None & Cefuroxime & Nephrolithiasis \\
\hline 21 & 60 & $\mathrm{~F}$ & Left flank pain & DM & Ciprofloxacin & $\begin{array}{l}\text { Nephrolithiasis and } \\
\text { UTI (Pseudomonas } \\
\text { aeruginosa) }\end{array}$ \\
\hline 22 & 76 & M & $\begin{array}{l}\text { Right upper quadrant pain, } \\
\text { nausea-vomiting }\end{array}$ & Heart failure & Dexketoprofen $25 \mathrm{mg}$ i.v. bid for 5 days and ceftriaxone & Acute cholecystitis \\
\hline 23 & 32 & $\mathrm{M}$ & Periumbilical pain & None & $\begin{array}{l}\text { Naproxen } 750 \mathrm{mg} \text { po qd for } 5 \text { days and amoxicillin/ } \\
\text { clavulanic acid }\end{array}$ & \\
\hline
\end{tabular}

bid, twice daily; CAD, coronary arterial disease; COPD, chronic obstructive pulmonary disease; DM, diabetes mellitus; F, female; HT, hypertension; M, male; qd, once daily; UTI, urinary tract infection; po, orally; IBS, irritable bowel syndrome; UTI, urinary tract infection.

bladder carcinoma, ovarian carcinoma, and breast carcinoma. Cancer diagnosis and surgical interventions had preceded the diagnosis of MP in all the patients with malignancy. Abdominal surgery for intestinal perforation was considered the leading cause of MP in 1 patient. Only 2 patients in the idiopathic group had cholecystectomy after the diagnosis of MP. Demographic and clinical data are presented in Table 1 .

Of the 24 patients in the idiopathic group, 13 (54.2\%) were men, and the median age was 53 years (range, 26-76 years). The median ages of idiopathic group and secondary group did not differ $(p=0.65)$. Despite a female dominance $(n=8 ; 67 \%)$ in the secondary MP group, female patients accounted for about half of the idiopathic MP group $(n=11 ; 46 \%)$. However, it did not reach statistical significance $(p=0.3)$. Five $(21 \%)$ patients in the idiopath- ic group had nephrolithiasis at presentation, while 1 patient was also diagnosed with acute cholecystitis. As opposed to the asymptomatic presentations of patients in the secondary group, the majority $(n=22 ; 92 \%)$ of patients in the idiopathic group presented with abdominal pain.

The demographic and clinical data of the idiopathic MP patients are presented in Table 2. Most of those patients were admitted to the hospital with severe localized abdominal pain. In addition to abdominal pain, 1 patient suffered from nausea and severe vomiting and another had diarrhea in conjunction with pain. Weight loss, fever of unknown origin, constipation, and ascites were not noted in the idiopathic MP population. The treatment of these patients mainly consisted of NSAID for pain relief and antibiotics. Antibiotics were prescribed in 15 patients, and NSAID were used in 16 patients. The pre- 
scribed antibiotics were cephalosporins in 10 patients, quinolones in 4 patients, and amoxicillin/clavulanic acid in 1 patient. All of the patients became symptom free, except for 1 patient in whom colchicine treatment was started after a lack of response to treatment with NSAID and moxifloxacin. That patient's severe abdominal pain decreased gradually after a 6-month treatment with colchicine. Because patients in the secondary group were asymptomatic or had symptoms related to primary disorders, additional treatments were not given to them.

There was no difference between the 2 groups regarding white blood cell counts, hemoglobin, platelet counts, liver function tests, or creatinine. The median protein and albumin levels were also lower in the secondary MP group than in the idiopathic group (7.3 vs. $6.9 ; p=0.05$, and 4.3 vs. 4.0 ; $p=0.04$, respectively). The erythrocyte sedimentation rate and C-reactive protein values were not available for the entire study population. Histopathological sampling of MP had not been performed in the patients with MP.

\section{Discussion}

In this study, the frequency of MP was $0.18 \%$ among patients undergoing abdominal CT examination. The patients with MP showed a slight female predominance and two thirds of them had no obvious related disorder. The incidence of MP has been reported to be in the range of $0.16-3.4 \%$ in previous studies $[5,7]$. The frequency of MP in this study (i.e., $0.18 \%$ ) is close to the $0.16 \%$ previously reported [7] but lower than 3.4\% [5]. The differences could be due to the methodology of this study, i.e., retrospective or prospective. Some of the retrospective studies used the keywords "mesenteric panniculitis" or "panniculitis" or "sclerosing mesenteritis" for screening of the CT reports $[2,6]$, while others reanalyzed all CT scans for the presence of MP [5, 7]. Because the patients were selected based on radiologic reports in the current study, we might have had a lower prevalence of MP in the study population. Although the gold standard for the diagnosis of MP is histopathological examination of the mesentery, none of our patients underwent histopathological examination and we considered them to have MP according to the MPlike findings on CT examinations [3].

The hallmark of this study was that the patients in the idiopathic group were treated with NSAID and/or several antibiotics. Although proof of the bacterial infection was evident in only 2 patients, symptomatic relief was achieved in all of the patients except 1 . Responses to brief anti-inflammatory and anti-infective treatments could indicate that the trigger event might be a self-limiting inflammation or infection that spread from adjacent structures to the mesenteric adipose tissue in most patients. Although no clear proof exists that a specific microorganism contributes to the development of MP, predisposition to immunosuppression, which is seen in malignancy or autoimmune disorders related to the disease itself or to its treatments, might explain why MP is more common in the immunosuppressive group of patients. Several atypical microorganisms such as Cryptococcus neoformans and Mycobacterium genavense have been reported in HIV patients in relation to MP $[14,15]$. On the other hand, M. tuberculosis and Vibrio cholera are suspected to be the infectious agents that cause MP in immunocompetent patients $[16,17]$. In addition, various acute abdominal inflammatory disorders in which enteric bacteria was involved in the etiopathogenesis, such as diverticulitis and acute appendicitis, have been reported in relation to MP [18].

The response to antibiotics could indicate that if the $\mathrm{MP}$ is of an infectious origin the microorganisms might spread from the gut or genitourinary tract. Bacterial translocation of microorganisms from the gut or urinary tract might localize an occult infection in adjacent mesenteric adipose tissue, thereby leading in the development of MP. Another probable explanation for acute cases may be viral enteritis [19]. The importance of intestinal microbiota and innate immunity in the pathogenesis of IBD has been better understood in recent years [20]. MP shares some features of adipose tissue changes in IBD, such as fat wrapping in Crohn's disease and a fat halo sign in Crohn's disease and ulcerative colitis $[8,21]$. Mesenteric adipose tissue itself, through adipokines, might be responsible for low-grade inflammation and subsequent fibrosis.

The results of the current study could indicate that this rare entity has a natural history different from that in Western countries presumably due to lower sanitary conditions, infections with several unidentified microorganisms, and genetic differences $[7,18]$. Therefore, there is a need for epidemiological studies from Asian and African countries in order to obtain more accurate epidemiologic data on MP. This retrospective study had some limitations; the CT database was searched using the terms "mesenteric panniculitis" and "sclerosing mesenteritis" to define the cohort. However, some patients could have been overlooked, and the prevalence of MP therefore could be underestimated. MP was diagnosed radiologically and none of the patients had a histopathologic diagnosis of MP and there was a lack of follow-up CT examinations, especially in the idiopathic group. 


\section{Conclusion}

In this study, a symptomatic idiopathic subgroup of patients with MP did not have associated disorders. Antibiotics and NSAID treatment was effective in most of the patients. Based on these findings, anti-inflammatory treatments beyond NSAID and surgery should be reserved for patients who are unresponsive to antibiotics and NSAID.

\section{Disclosure Statement}

The authors declare no conflicts of interest.

\section{References}

1 Coulier B: Mesenteric panniculitis. Part 1: MDCT - pictorial review. JBR-BTR 2011;94: 229-240.

2 Badet N, Sailley N, Briquez C, et al: Mesenteric panniculitis: still an ambiguous condition. Diagn Interv Imaging 2015;96:251-257.

3 Emory TS, Monihan JM, Carr NJ, et al: Sclerosing mesenteritis, mesenteric panniculitis and mesenteric lipodystrophy: a single entity? Am J Surg Pathol 1997;21:392-398.

4 Horton KM, Lawler LP, Fishman EK: CT findings in sclerosing mesenteritis (panniculitis): spectrum of disease. Radiographics 2003;23:1561-1567.

5 Coulier B: Mesenteric panniculitis. Part 2: prevalence and natural course: MDCT prospective study. JBR-BTR 2011;94:241-246.

6 Wilkes A, Griffin N, Dixon L, et al: Mesenteric panniculitis: a paraneoplastic phenomenon? Dis Colon Rectum 2012;55:806-809.

7 van Putte-Katier N, van Bommel EF, Elgersma $\mathrm{OE}$, et al: Mesenteric panniculitis: prevalence, clinicoradiological presentation and 5-year follow-up. Br J Radiol 2014;87: 20140451.

8 Hussein MR, Abdelwahed SR: Mesenteric panniculitis: an update. Expert Rev Gastroenterol Hepatol 2015;9:67-78.
9 van Breda Vriesman AC, Schuttevaer HM, Coerkamp EG, et al: Mesenteric panniculitis: US and CT features. Eur Radiol 2004;14: 2242-2248.

10 Bala A, Coderre SP, Johnson DR, et al: Treatment of sclerosing mesenteritis with corticosteroids and azathioprine. Can J Gastroenterol 2001;15:533-535.

11 Akram S, Pardi DS, Schaffner JA, et al: Sclerosing mesenteritis: clinical features, treatment, and outcome in ninety-two patients. Clin Gastroenterol Hepatol 2007;5:589-596; quiz 523-524.

12 Endo K, Moroi R, Sugimura M, et al: Refractory sclerosing mesenteritis involving the small intestinal mesentery: a case report and literature review. Intern Med 2014;53:1419_ 1427.

13 Masulovic D, Jovanovic M, Ivanovic A, et al: Sclerosing mesenteritis presenting as a pseudotumor of the greater omentum. Med Princ Pract 2016;25:93-95.

14 Alonso Socas MM, Valls RA, Gomez Sirvent $\mathrm{JL}$, et al: Mesenteric panniculitis by cryptococcal infection in an HIV-infected man without severe immunosuppression. AIDS 2006;20:1089-1090.

15 Borde JP, Offensperger WB, Kern WV, et al: Mycobacterium genavense specific mesenteritic syndrome in HIV-infected patients: a new entity of retractile mesenteritis? AIDS 2013; 27:2819-2822.
16 Ege G, Akman H, Cakiroglu G: Mesenteric panniculitis associated with abdominal tuberculous lymphadenitis: a case report and review of the literature. Br J Radiol 2002;75: 378-380.

17 Roginsky G, Mazulis A, Ecanow JS, et al: Mesenteric panniculitis associated with Vibrio cholerae infection. ACG Case Rep J 2015;3: 39-41.

18 Smith ZL, Sifuentes H, Deepak P, et al: Relationship between mesenteric abnormalities on computed tomography and malignancy: clinical findings and outcomes of $359 \mathrm{pa}$ tients. J Clin Gastroenterol 2013;47:409-414.

19 Ehrenpreis ED, Roginsky G, Gore RM: Clinical significance of mesenteric panniculitislike abnormalities on abdominal computerized tomography in patients with malignant neoplasms. World J Gastroenterol 2016;22: 10601-10608.

20 Ohkusa T, Koido S: Intestinal microbiota and ulcerative colitis. J Infect Chemother 2015;21: 761-768.

21 Amitai MM, Arazi-Kleinman T, Avidan B, et al: Fat halo sign in the bowel wall of patients with Crohn's disease. Clin Radiol 2007;62: 994-997. 